\title{
Comparison of the Resonant Frequency Determination of a Microstrip Patch Antenna using ANN and Analytical Methods
}

\author{
Lahcen Aguni $^{1}$, Samira Chabaa ${ }^{2}$, Saida Ibnyaich ${ }^{1}$, Abdelouhab Zeroual ${ }^{2}$ \\ ${ }^{1}$ Department of Physics, Cadi Ayyad University Faculty of Sciences, Semlalia Marrakesh, Morocco \\ ${ }^{2}$ Industrial Engineering Department, National School of Applied Sciences, Ibn Zohr University, Agadir, Morocco
}

\begin{abstract}
Article Info
Article history:

Received Jan 13, 2017

Revised Feb 24, 2017

Accepted Mar 15, 2017

Keywords:

Artificial Neural Networks (ANN)

Multi Layer Perceptron (MLP)

Microstrip patch antenna

Resonant frequency

ABSTRACT

In this paper we are interested to calculate the resonant frequency of rectangular patch antenna using artificial neural networks based on the multilayered perceptrons. The artificial neural networks built, transforms the inputs which are, the width of the patch $\mathrm{W}$, the length of the patch $\mathrm{L}$, the thickness of the substrate $\mathrm{h}$ and the dielectric permittivity $\varepsilon_{r}$ to the resonant frequency fr which is an important parameter to design a microstrip patch antenna.The proposed method based on artificial neural networks is compared to some analytical methods using some statistical criteria. The obtained results demonstrate that artificial neural networks are more adequate to achieve the purpose than the other methods and present a good argument with the experimental results available in the literature. Hence, the artificial neural networks can be used by researchers to predict the resonant frequency of a rectangular patch antenna knowing length $(\mathrm{L})$, width $(\mathrm{W})$, thickness $(\mathrm{h})$ and dielectric permittivity $\left(\varepsilon_{r}\right)$ with a good accuracy.
\end{abstract}

Copyright $@ 2017$ Institute of Advanced Engineering and Science. All rights reserved.

\section{Corresponding Author:}

Departement of Electrical and Computer Engineering,

National Chung Cheng University,

168 University Road, Minhsiung Township, Chiayi County 62102, Taiwan, ROC.

\section{INTRODUCTION}

The Microstrip patch antennas become one of the most popular antenna types used in many applications and in several fields like, GPS, Bluetooth, LTE, mobile phone, wireless application, satellite communication ... The patch antennas are compatible with planar and non-planar surfaces [1]. These antennas are characterized by several advantages. In one hand, the low cost to manufacture it from compatible circuit with hybrid circuits and MMIC (Monolithic Microwave Integrated Circuit) [1,2]. In the other hand, they can be mounted on any surface due to their low weight and low volume. Furthermore, these advantages have recently increased their use in many areas and have led to improve their performance.

However, microstrip antennas have the drawback of narrow bandwidth, low gain and can operate effectively only in the vicinity of the resonant frequency. For this reason and in order to design a patch antenna it's important to determine the resonant frequency accurately [3].

In the literature, artificial neural networks (ANN) models have been built usually for the analysis of microstrip antennas. They are called the data-processing models inspired from the structure and behavior of the biological neurons [4]. The computational capability of ANN is given by connection weights, architecture and training algorithm [5]. ANNs have been used in different fields of science, technology and in the design of microstrip patch antenna [6]. ANNs have been used to calculate the resonant frequency of a rectangular patch antenna at a given length, width, height and dielectric constant [7]. In [8] artificial neural models based on the MLPs and the RBFNs are presented for computing the resonant frequency of circular microstrip antennas with thin and thick substrates. With the suitable learning algorithm, the ANN can be trained to achieve, from input variables, a minimum error between the network output and the target. 
In this paper, we are interested to apply the artificial neural network method based on the multi layer perceptron (MLP) to calculate the resonant frequency of the rectangular patch antenna for a number of samples. The length $(\mathrm{L})$, the width $(\mathrm{W})$, the thickness $(\mathrm{h})$ of the substrate and the dielectric permittivity $\left(\varepsilon_{r}\right)$ are used as inputs of the artificial neural network model. Some statistical criteria such as MSE, RMSE, MAPE and R are used to compare the approximation of the resonant frequency using the ANN and those given by the analytical methods available in the literature in particular those proposed by James and al [9], b.Sengupta, D.L [10] and Güney, K [11].

\section{DESCRIPTION OF RECTANGULAR PATCH ANTENNA}

Microstrip antenna is a very small conducting patch with dimensions of width (W), length (L) over a ground plane with a substrate thickness $(\mathrm{h})$. The patch is generally made of conducting material such as copper built on a ground plane separated by dielectric substrate $\left(\varepsilon_{\mathrm{r}}\right)$ usually in the range of $2.2 \leq \varepsilon_{\mathrm{r}} \leq 12$, depending on the used material [1]. The radiating patch may be square, rectangular, thin strip (dipole), circular, elliptical, triangular, or any other configuration.

The transmission-line model represents a rectangular microstrip antenna as an array of two radiating narrow apertures (slots), each of width (W) and height (h), separated by a distance (L) [1].

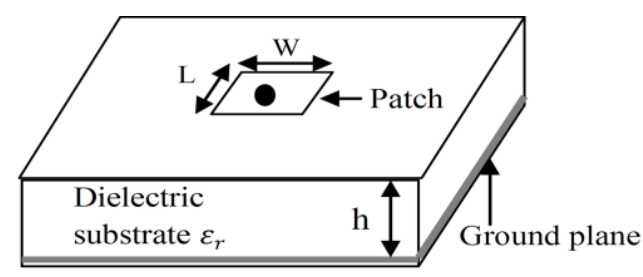

Figure 1. Rectangular patch antenna

The fringing fields makes the microstrip line look wider electrically compared to its physical dimensions $\mathrm{L}_{\mathrm{eff}}>\mathrm{L}$, the length of the patch has been extended by $\Delta \mathrm{L}$ on each side; the effective length of the patch is now $\mathrm{L}_{\mathrm{eff}}=\mathrm{L}+2 \Delta \mathrm{L}[1]$.

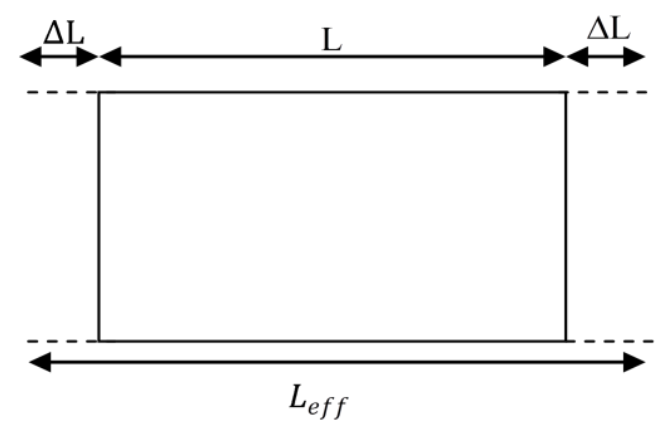

Figure 2. Radiating element extended by $\Delta \mathrm{L}$

\section{APPROXIMATION OF THE RESONANT FREQUENCY}

A number of methods available to determine the resonant frequency of rectangular patch antennas. In this part, we are interested to calculate the resonant frequency with three theoretical methods proposed by James and al [9], Sengupta, D.L [10] and Güney, K [11].

Consider a microstrip antenna with a rectangular patch of width $\mathrm{W}$ and length $\mathrm{L}$ over a ground plane with a substrate of thickness $h$ and a relative dielectric constant $\varepsilon_{\mathrm{r}}$, as shown in Figure 1. The approximate equations to calculate the resonant frequency is proposed in this section. 


\subsection{James and al method}

The resonant frequency $\mathrm{f}_{\mathrm{r}}$ suggested by James and al [9] is given by:

$$
\mathrm{f}_{\mathrm{r}}=\mathrm{f}_{0} \cdot \frac{\varepsilon_{\mathrm{r}}}{\sqrt{\varepsilon_{\text {reff }}(\mathrm{L}) \cdot \varepsilon_{\text {reff }}(\mathrm{W})}} \cdot \frac{1}{(1+\Delta)}
$$

The effective permittivity in function of $u$ is expressed by:

$$
\varepsilon_{\text {reff }}(\mathrm{u})=\frac{\varepsilon_{\mathrm{r}}+1}{2}+\frac{\varepsilon_{\mathrm{r}}-1}{2 \sqrt{1+10 \frac{\mathrm{h}}{\mathrm{u}}}}
$$

with:

$$
\Delta=\frac{\mathrm{h}}{\mathrm{L}} \cdot\left[0.882+\frac{0.164\left(\varepsilon_{\mathrm{r}}-1\right)}{\varepsilon_{\mathrm{r}}{ }^{2}}+\frac{\left(\varepsilon_{\mathrm{r}}+1\right)}{\varepsilon_{\mathrm{r}} \cdot \pi}\left\{0.758+\ln \left(\frac{\mathrm{L}}{\mathrm{h}}+1.88\right)\right\}\right]
$$

and:

$$
\mathrm{f}_{0}=\frac{\mathrm{c}}{2 \mathrm{~L} \sqrt{\varepsilon_{\mathrm{r}}}} ; \quad \mathrm{c}=3.10^{8} \mathrm{~m} / \mathrm{s}
$$

\subsection{Sengupta D.L method} expression:

The expression of the resonant frequency approximated by Sengupta, D, L [10] takes the following

$$
\mathrm{f}_{\mathrm{r}}=\mathrm{f}_{0}\left[\frac{1-\frac{2 \mathrm{~h}}{\varepsilon_{\text {reff }} \mathrm{L} \pi \alpha}}{1+\frac{2 \mathrm{~h}}{\varepsilon_{\text {reff }} \mathrm{L} \pi \alpha} \ln \left(\frac{\sqrt{\varepsilon_{\text {reff }}} 2 \mathrm{~L}}{\gamma \mathrm{h}}\right)}\right]
$$

The effective dielectric constant is given as:

with:

$$
\varepsilon_{\text {reff }}=\frac{\varepsilon_{\mathrm{r}}+1}{2}+\frac{\varepsilon_{\mathrm{r}}-1}{2}\left(1+10 \frac{\mathrm{h}}{\mathrm{W}}\right)^{-\frac{1}{2}}
$$

$$
\begin{gathered}
\alpha=1+1.393\left(\frac{\mathrm{h}}{\mathrm{W}}\right)+0.667\left(\frac{\mathrm{h}}{\mathrm{W}}\right) \ln \left(\frac{\mathrm{W}}{\mathrm{h}}+1.444\right) \\
\mathrm{f}_{0}=\frac{\mathrm{c}}{2 \mathrm{~L} \sqrt{\varepsilon_{\text {reff }}}} \\
\gamma=1.78107 \\
\mathrm{c}=3.10^{8} \mathrm{~m} / \mathrm{s}
\end{gathered}
$$

\subsection{Sengupta D.L method}

To calculate the resonant frequency, Güney, K [11] proposes the following formula:

$$
\mathrm{f}_{\mathrm{r}}=\frac{\mathrm{c}}{2 \sqrt{\varepsilon_{\text {reff }}} \mathrm{L}_{\text {eff }}}
$$

The effective dielectric constant is defined as:

$$
\varepsilon_{\text {reff }}=\frac{\varepsilon_{\mathrm{r}}+1}{2}+\frac{\varepsilon_{\mathrm{r}}-1}{2}\left(1+10 \frac{\mathrm{h}}{\mathrm{W}}\right)^{-\mathrm{ab}}
$$


where:

$$
\begin{gathered}
a=1+\frac{1}{49} \ln \left\{\frac{\left(\frac{W}{h}\right)^{4}+\frac{W^{2}}{(52 h)^{2}}}{\left(\frac{W}{h}\right)^{4}+0.432}\right\}+\frac{1}{18.7} \ln \left\{1+\left(\frac{W}{18.1 h}\right)^{3}\right\} \\
b=0.564\left(\frac{\varepsilon_{\mathrm{r}}-0.9}{\varepsilon_{\mathrm{r}}+3}\right)^{0.053}
\end{gathered}
$$

The effective length of the patch is:

$$
\mathrm{L}_{\mathrm{eff}}=\mathrm{L}+2 \Delta \mathrm{L}
$$

with:

$$
\Delta \mathrm{L}=\mathrm{h} . \frac{21.4075+\mathrm{k}_{0} \mathrm{~h}\left(184.6614-1.1475 \varepsilon_{\mathrm{r}}+8.5 \mathrm{k}_{0} \mathrm{~h}\right)-1.35 \varepsilon_{\mathrm{r}}}{18\left(1+10.85 \mathrm{k}_{0} \mathrm{~h}+8.5 \mathrm{k}_{0}{ }^{2} \mathrm{~h}^{2}\right)}
$$

if $\quad \frac{\mathrm{h}}{\lambda_{\mathrm{s}}} \leq 0.11$

$$
\Delta \mathrm{L}=\mathrm{h} . \frac{6.8955+\mathrm{k}_{0} \mathrm{~h}\left(61.062-0.3315 \varepsilon_{\mathrm{r}}+8.5 \mathrm{k}_{0} \mathrm{~h}\right)-0.39 \varepsilon_{\mathrm{r}}}{5.2\left(1+10.85 \mathrm{k}_{0} \mathrm{~h}+8.5 \mathrm{k}_{0}{ }^{2} \mathrm{~h}^{2}\right)}
$$

if $\quad \frac{\mathrm{h}}{\lambda_{\mathrm{s}}}>0.11$

$$
\mathrm{c}=3.10^{8} \mathrm{~m} / \mathrm{s}
$$

The wave vector $\mathrm{k}_{0}$ and the wave length $\lambda_{0}$ are expressed by:

$$
\mathrm{k}_{0}=\frac{2 \pi}{\lambda_{0}} \text { and } \lambda_{0}=2.08 \mathrm{~L} \sqrt{\varepsilon_{\mathrm{r}}}
$$

\section{ARTIFICIAL NEURAL NETWORK METHOD}

Artificial neural networks are computational models inspired from the structure and behavior of biological neurons and recently became a modeling and design tool that is an alternative of numerical models and analytical models [4]. The most used model of artificial neural networks nowadays is Multilayer perceptron (MLP) [15].

Multilayer perceptrons as a feedforward neural network trained with the standard backpropagation algorithm have been applied successfully to solve many problems in a supervised manner [12]. The architecture of a multilayer with an input layer, one hidden layer or intermediate layer and an output layer is given in Figure 3.

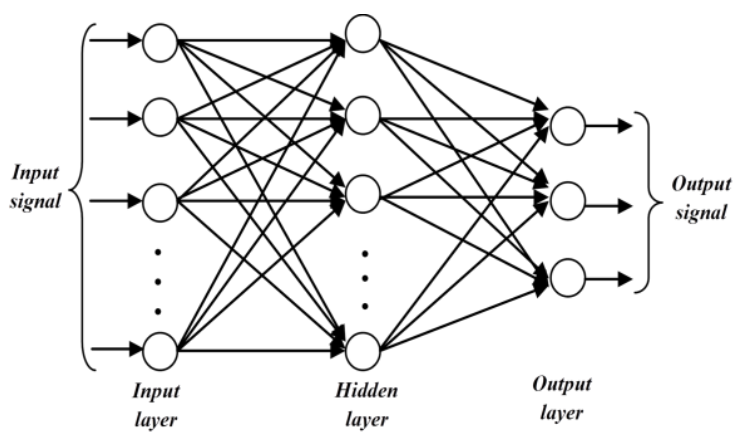

Figure 3. Multilayer perceptrons structure 


\section{MLP STRUCTURE}

An artificial neural network is a mathematical function used to predict data; the structure used in this network has four inputs: the length of the patch (L), the width (W), the thickness of the dielectric substrate (h) and the dielectric permittivity $\left(\varepsilon_{\mathrm{r}}\right)$.The desired output is the resonant frequency $\left(\mathrm{f}_{\mathrm{r}}\right)$.To build ANN structure, you have to determine: number of layers, number of neurons in each layer, neurons activation function and learning algorithm.

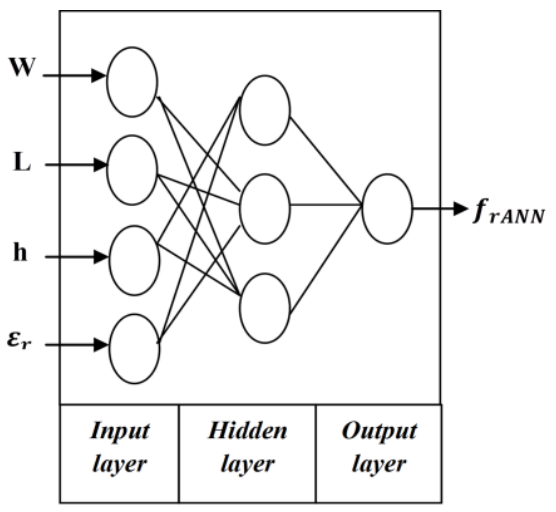

Figure 4. MLP structure

The database used is obtained from measurements performed by Kara M [13] and [14]; the identification of the MLP neural networks requires two steps. The first one is the determination of the network structure where the distribution of data is given in the table below:

Table 1. Database distribution

\begin{tabular}{ccc}
\hline $\begin{array}{c}\text { Database } \\
\text { distribution }\end{array}$ & Percentage & $\begin{array}{c}\text { Number of } \\
\text { samples }\end{array}$ \\
\hline Training & $80 \%$ & 26 \\
Validation & $00 \%$ & 00 \\
Testing & $20 \%$ & 07 \\
\hline
\end{tabular}

The second one is the identification of parameters (learning of the neural networks): the number of hidden layers, the number of neurons in hidden layer, the appropriate learning algorithm and the most suitable transfer function for the network.

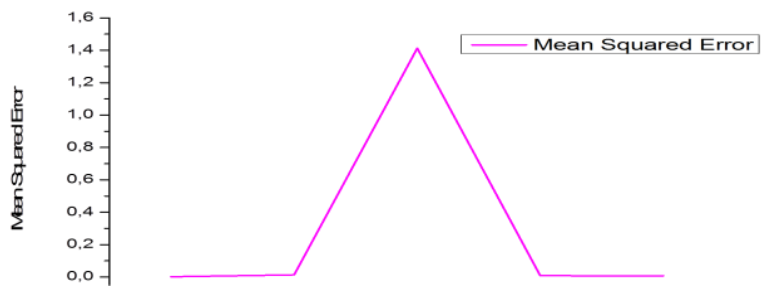

Figure 5. Variation of MSE for different number of hidden layers 


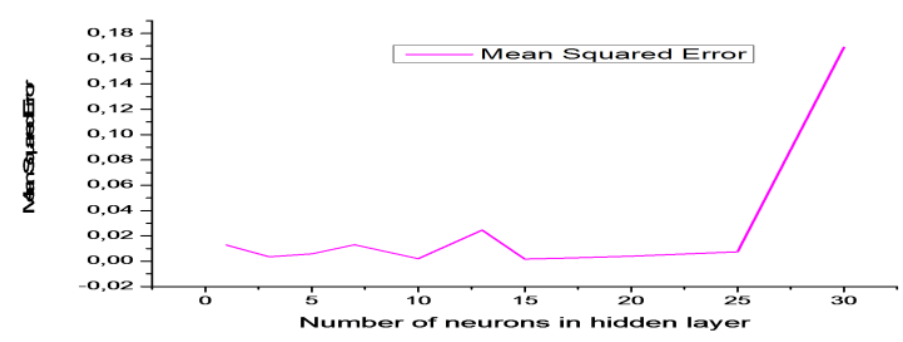

Figure 6. Variation of MSE for different number of neurons in hidden layer

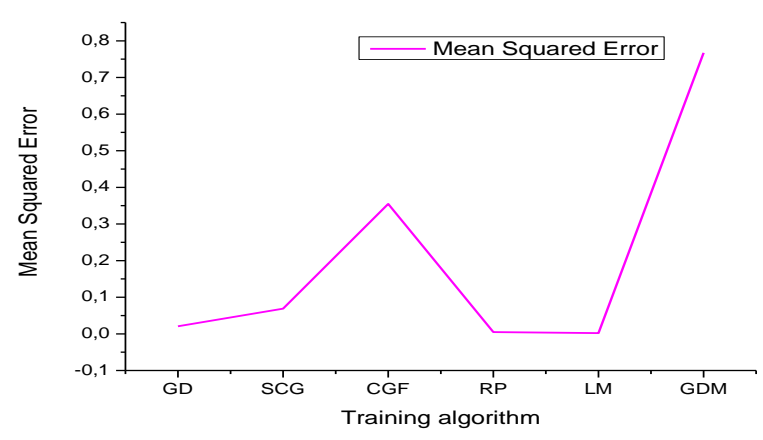

Figure 7. Variation of MSE for different training algorithms

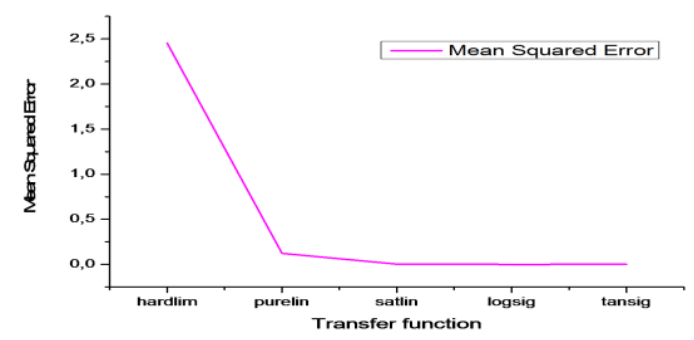

Figure 8. Variation of MSE for different transfer functions

The optimum network structure for the proposed problem after multiple training consists of three layers MLP with a number of neurons, the input layer with four input neurons, one hidden layer with 10 hidden neurons and one output neurons in the output layer. While the most suitable learning algorithm is Levenberg Marquardt (LM).The appropriate transfer function in the hidden layer is sigmoid function, while the transfer function used in the output layer is the linear function.

\section{RESULTS AND DISCUSSION}

In this study our goal is first to calculate the resonant frequency of the rectangular patch antenna which depends on the dimensions of the antenna; length $(\mathrm{L})$, width $(\mathrm{W})$, substrate thickness $(\mathrm{h})$ and dielectric permittivity $\left(\varepsilon_{\mathrm{r}}\right)$, secondly we perform a comparison of the obtained results using artificial neural network with three analytical methods. 

equations:

The performance of our results is checked using statistical criteria giving by the following

Mean Square Error:

$$
\operatorname{MSE}=\left(\frac{1}{n}\right) \sum_{i=1}^{n}\left(t_{i}-\alpha_{i}\right)^{2}
$$

Mean Absolute Percentage Error:

$$
\operatorname{MAPE}=\left(\frac{1}{n} \sum_{i=1}^{n}\left|\frac{t_{i}-\alpha_{i}}{t_{i}}\right|\right) \times 100
$$

Absolute Fraction of Variance:

$$
\mathrm{R}^{2}=\left(1-\left(\frac{\sum_{\mathrm{i}=1}^{\mathrm{n}}\left|\mathrm{t}_{\mathrm{i}}-\alpha_{\mathrm{i}}\right|^{2}}{\sum_{\mathrm{i}=1}^{\mathrm{n}} \mathrm{t}_{\mathrm{i}}}\right)\right) \times 100
$$

where: $\mathrm{n}$ is the total number of samples, $\mathrm{t}_{\mathrm{i}}$ and $\alpha_{\mathrm{i}}$ represent respectively target and output data.

In the table below we have grouped the values of some statistical criteria exploited in this study for the analytical methods and the ANN method:

Table 2. Statistical criteria obtained for various methods

\begin{tabular}{cccc}
\hline Variable & MSE & MAPE & $\mathrm{R}$ \\
\hline James and al & 1.1288 & 19.432 & 79.22 \\
Sengupta, & 0.1031 & 5.1538 & 98.10 \\
D.L & & & \\
Guney, K & 1.1661 & 19.395 & 78.54 \\
ANN & 0.0020 & 0.2886 & 99.96 \\
\hline
\end{tabular}

As shown in Figure 9 the total number of 55 epochs is required to reduce MSE level to a low value.

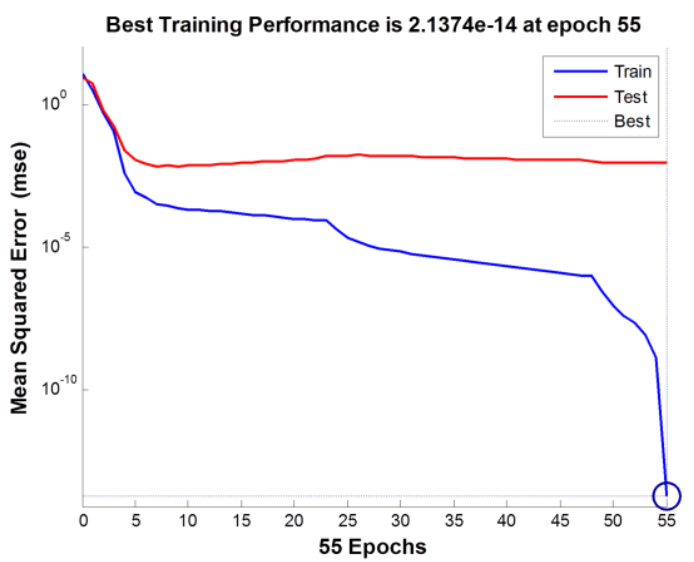

Figure 9. Mean squared error

The regression coefficient R for our MLP network which describes the relationship between the predicted values (outputs) and the observed values (targets) is shown in the Figure 10. The data should fall along a 45 degree line, for a perfect fit, where the network outputs are equal to the targets. For this problem, the fit is reasonably good for all data sets, with $R$ values in each case is approximately $R=1$, the value of this coefficient shows that the network built with structure (4-10-1) is performing. 

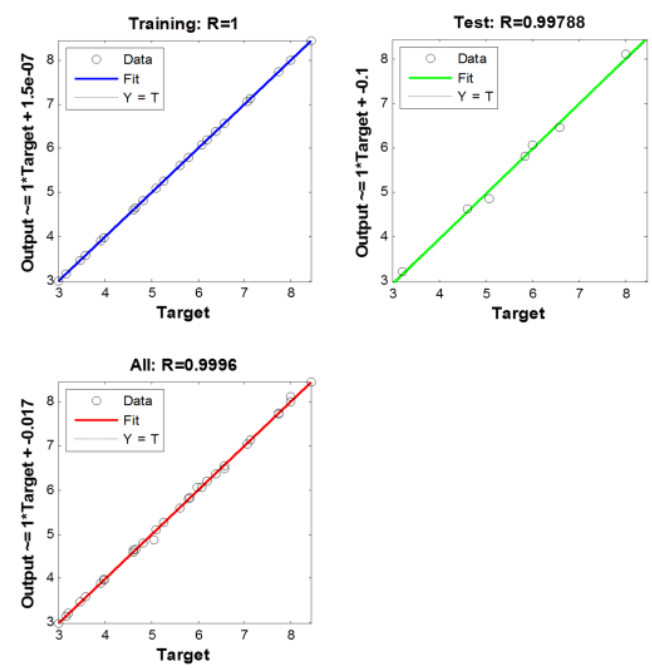

Figure 10. Regression curves of trained ANN

To provide additional verification of network performance we plot in Figure 11 the resonant frequency vs. the number of samples for: experimental method, analytical methods and ANN method.

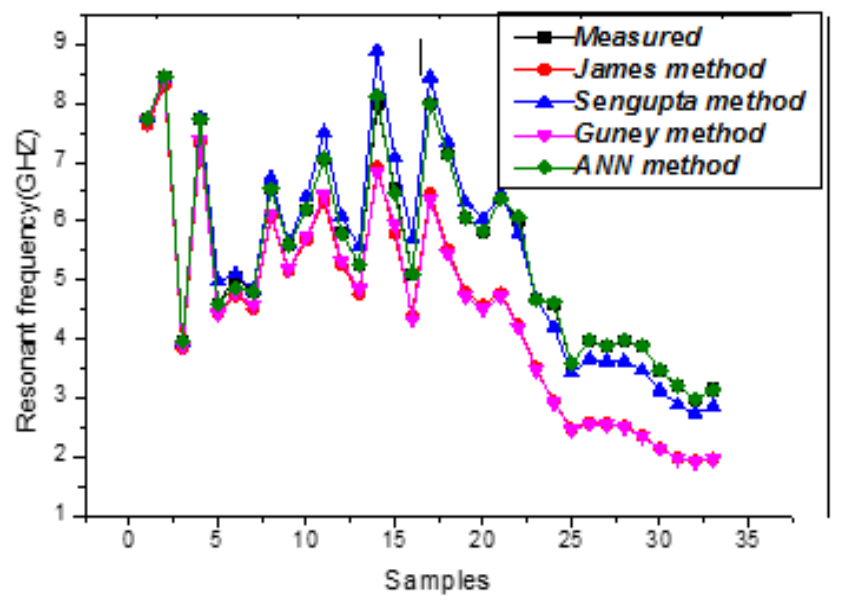

Figure 11. Resonant frequency vs. samples

We can see from the comparison between the artificial neural network method and the analytical methods in Figure 11 and in Table 2 that; the obtained results by ANN method using the learning algorithm Levenberg-Marquardt LM are in perfect adaptation with the experimental results presented by KARA, M [13] and [14].

\section{CONCLUSION}

In this paper, we are interested to apply the artificial neural networks method based on the multilayer perceptrons (MLP) to calculate the resonant frequency of the rectangular patch antenna. The proposed method using ANN is compared to some analytical methods in term of statistical criteria. The obtained results demonstrate that ANN is more adequate to rich the purpose than the other methods because 
it presents a good argument with the experimental results. Consequently, artificial neural networks can be used by researchers to predict the resonant frequency of a rectangular patch antenna using length $(\mathrm{L})$, width $(\mathrm{W})$, thickness $(\mathrm{h})$ and dielectric permittivity $\left(\varepsilon_{\mathrm{r}}\right)$ as the network inputs. The correlation value $\mathrm{R}$ is $99.96 \%$ which indicates the good agreement between the measured and ANN predicted values. Therefore, the ANN can further be employed as a tool to obtain the geometric dimensions of the microstrip patch antenna with a high accuracy.

\section{REFERENCES}

[1] Canstantine. A. Balanis, "Antenna Theory, Analysis and Design second edition", John Wiley \& Sons, New York, 2009.

[2] Adil Bouhous , "Artificial Neural Network In The Design Of Rectangular Microstrip Antenna", Advanced Computational Intelligence: An International Journal (ACII), vol.2, no.2, April 2015.

[3] D. Karaboga; K. Guney; S. Sagiroglu; M. Erler, "Neural computation of resonant frequency of electricallythin and thick rectangular microstrip antennas", Microwaves, Antennas and Propagation, IEE Proceedings, vol.146, no.2, pp. 155 - 159, April 1999.

[4] Lotfi Merad; Fethi Tarik Bedimerad; Sidi Mohamed Meriah; Sidi Ahmed Djennas , "Neural Networks for Synthesis and Optimization of Antenna Arrays", Radioengineering, vol.16, no.1, April 2007.

[5] Amit Kumar Yadav; Hasmat Malik; A.P. Mittal , "Artificial Neural Network Fitting Tool Based Prediction Of Solar Radiation For Identifying Solar Power Potential”, Journal of Electrical Engineering.

[6] Bablu Kumar Singh, "Design of Rectangular Microstrip Patch Antenna based on Artificial Neural Network Algorithm", 2015 2nd International Conference on Signal Processing and Integrated Networks (SPIN). 978-14799-5991-4/15/\$31.00 @2015 IEEE.

[7] Bishal Dey Sarkar; Sonali Shankar; Anita Thakur and Himanshu Chaurasiya, "Resonant Frequency Determination of Rectangular Patch Antenna using Neural Network", 2015 1st International Conference on Next Generation Computing Technologies (NGCT-2015) Dehradun, India, 4-5 September 2015. 978-1-4673-6809-4/15/\$31.00 (C)2015 IEEE

[8] Celal Yildiz; Sinan Gultekin; Kerim Guney; Seref Sagiroglu, "Neural Models for the Resonant Frequency of Electrically Thin and Thick Circular Microstrip Antennas and the Characteristic Parameters of Asymmetric Coplanar Waveguides Backed with a Conductor", Int. J. Electron. Commun. (AE" U) 56(2002) No. 6, 396-406.

[9] James, J.R.; Hall, P.S. (Eds.), "Handbook of microstrip antennas", (Peter Peregrinus Ltd., 1989), vols. 1 and 2.

[10] Sengupta, D.L , "Approximate expression for the resonant frequency of a rectangular patch antenna", Electron. Lett. 1983, vol.19, no.20, pp. 834-835.

[11] Guney, K, "A new edge extension expression for the resonant frequency of electrically thick rectangular microstrip antennas", Int: J. Electron., 1993, vol.75, no.4, pp. 767-770

[12] Simon Haykin, "Neural Network, A comprehensive foundation", 2nd Ed., Pearson, ISBN: 81-7808-300-0, 2004.

[13] Kara, M, "The resonant frequency of rectangular microstrip antenna elements with various substrate thicknesses", Microw. Opt. Tecknol. Lett, 1996, vol.11, no.2, pp. 55-59.

[14] Kara, M. , "Closed-form expressions for the resonant frequency of rectangular microstrip antenna elements with thick substrates", Microw. Opt. Technol. Lett., 1996, vol.12, no.3, pp. 131-136.

[15] Zeinalizadeh, N.; Shojaie, A. A.; Shariatmadari, M. , "Modeling and analysis of bank customer satisfaction using neural networks approach", International Journal of Bank Marketing, vol.33, no. 6, 2015, pp. 717-732. 